\title{
Erratum to: Cost-effective enhanced iron bioavailability in rice grain grown on calcareous soil by sulfur mediation and its effect on heavy metals mineralization
}

Pia Muhammad Adnan Ramzani ${ }^{1,2}$ - Muhammad Khalid ${ }^{1}$ - Shazia Anjum ${ }^{2}$. Waqas-ud-Din Khan $^{3}$ • Shafaqat Ali ${ }^{4}$ - Fakhir Hannan ${ }^{4}$ - Muhammad Iqbal ${ }^{4}$

Published online: 2 December 2016

(C) Springer-Verlag Berlin Heidelberg 2016

Erratum to: Environ Sci Pollut Res

DOI 10.1007/s11356-016-7892-6

The name of the first author was erroneously split into two names. The author's correct full name is Pia Muhammad Adnan Ramzani.

The original article was corrected.

The online version of the original article can be found at http://dx.doi. org/10.1007/s11356-016-7892-6.

Muhammad Iqbal

iqbal.farhad@gmx.at

1 Institute of Soil and Environmental Sciences, University of Agriculture Faisalabad, Faisalabad 38040, Pakistan

2 Cholistan Institute of Desert Studies, The Islamia University of Bahawalpur, Bahawalpur 63100, Pakistan

3 Sustainable Development Study Center, Government College University, Lahore 54000, Pakistan

4 Department of Environmental Sciences and Engineering, Government College University, Allama Iqbal Road, Faisalabad 38000, Pakistan 